\title{
PENGUKURAN KINERJA PERUSAHAAN PADA PT. YYY DENGAN MENGGUNAKAN METODE BALANCED SCORECARD
}

\author{
Richardson Harjanto Nurdin \\ Program Studi Magister Manajemen Universitas Tarumanagara \\ richardson_harjanto@yahoo.co.id
}

\begin{abstract}
This research aims to find out how the company performance of PT. YYY can be measured and evaluated by using the balanced scorecard method. The research using the balanced scorecard method aims to evaluate four important perspectives at PT. YYY which includes financial perspective, internal business process perspective, customer perspective, and growth and learning perspective in the period of the year 2013 to 2017.

Abstrak : Penelitian ini bertujuan untuk mencari tahu bagaimana kinerja perusahaan pada PT. YYY dapat diukur dan dievaluasi dengan menggunakan metode balanced scorecard. Penelitian dengan menggunakan metode balanced scorecard ini bertujuan untuk mengevaluasi empat perspektif penting pada PT. YYY yang meliputi perspektif keuangan, perspektif proses bisnis internal, perspektif pelanggan, dan perspektif pertumbuhan dan pembelajaran dalam periode tahun 2013 sampai dengan 2017.
\end{abstract}

Keywords: Performance, Balanced Scorecard, Financial Perspective, Internal Business Process Perspective, Growth and Learning Perspective, Customer Perspective.

\section{PENDAHULUAN}

Pengukuran kinerja pada perusahaan merupakan salah satu kegiatan evaluasi pada perusahaan yang perlu untuk dilakukan. Tujuan dari dilakukannya pengukuran dan evaluasi terhadap kinerja perusahaan yaitu untuk mengetahui apakah hasil yang telah tercapai sudah cukup baik atau perlu ditingkatkan. Hasil pengukuran terhadap kinerja suatu perusahaan dapat dijadikan sebagai masukan atau pembelajaran bagi perusahaan itu sendiri untuk dapat memperbaiki kelemahan-kelemahan yang ada dan terus mengembangkan segala potensi yang dimilikinya untuk dapat terus berkembang di masa depan.

\section{TINJAUAN PUSTAKA}

\section{Kinerja}

Kinerja dapat didefinisikan sebagai hasil pekerjaan yang mempunyai hubungan dengan tujuan strategis organisasi, kepuasan konsumen, dan memberikan kontribusi pada ekonomi (Wibowo, 2007). Kinerja juga dapat diartikan sebagai suatu tampilan keadaan secara utuh atas perusahaan selama periode waktu tertentu, merupakan hasil atau prestasi yang dipengaruhi oleh kegiatan operasional perusahaan dalam memanfaatkan sumber-sumber daya yang dimiliki (Helfert, 2002). Sedangkan menurut Mulyadi (2001), kinerja adalah istilah umum yang digunakan untuk menunjukkan sebagian atau seluruh tindakan atau aktivitas dari suatu organisasi pada suatu periode (Mulyadi, 2001). 


\section{Konsep Balanced Scorecard}

Munculnya metode Balanced Scorecard dapat membantu perusahaan di dalam melakukan pengukuran dan evaluasi terhadap hasil dari kinerja perusahaan yang telah tercapai di masa lalu. Balanced Scorecard merupakan sebuah metode di dalam manajemen strategik yang dikembangkan oleh Drs. Robert Kaplan (Harvard Business School) dan David Norton pada akhir abad ke 20. Balanced Scorecard berasal dari dua kata yaitu balanced (berimbang) dan scorecard (kartu skor). Balanced berarti adanya keseimbangan antara performa keuangan dan performa nonkeuangan dalam jangka pendek maupun jangka panjang, antara performa yang bersifat internal dan performa yang bersifat eksternal. Sedangkan scorecard yaitu kartu yang digunakan untuk mencatat skor hasil kinerja perusahaan. Kartu skor juga dapat digunakan untuk merencanakan skor yang hendak diwujudkan oleh perusahaan dimasa depan (Robert S. Kaplan, David P. Norton, 1996). ${ }^{1}$ Jadi, balanced scorecard dapat dikatakan sebagai sebuah metode untuk memberikan penilaian terhadap hasil kinerja perusahaan.

\section{METODOLOGI PENELITIAN}

Penelitian ini merupakan penelitian deskriptif. Penelitian ini dilakukan pada periode tahun 2013 sampai dengan tahun 2017. Penelitian ini menggunakan sumber data-data sekunder dari objek penelitian yaitu PT. YYY. Data-data sekunder meliputi hasil wawancara dan observasi pada PT. YYY, dan beberapa catatan laporan dari PT. YYY yang meliputi laporan keuangan, laporan laba rugi, daftar absen karyawan, laporan hasil produksi, laporan tingkat ketepatan waktu karyawan dalam menyelesaikan pekerjaan, dan laporan tingkat kepuasan karyawan dalam bekerja.

\section{PEMBAHASAN}

\section{Penilaian Kinerja pada PT. YYY dengan pendekatan Balanced Scorecard}

Pengukuran kinerja pada perusahaan dengan menggunakan metode balanced scorecard dapat dilakukan dengan melakukan evaluasi pada empat perspektif penting di dalam perusahaan (Kaplan dan Norton, 1996), yaitu perspektif keuangan, perspektif proses bisnis internal, perpektif pelanggan, dan perspektif pertumbuhan dan pembelajaran. ${ }^{2}$

\section{Penilaian Kinerja pada Perspektif Keuangan}

Penilaian kinerja pada perspektif keuangan dilakukan melalui analisis terhadap laporan keuangan PT. YYY sebagai sumber untuk melakukan penilaian. Laporan keuangan pada PT. YYY yang digunakan oleh penulis berasal dari tahun 2013 sampai dengan tahun 2017. Terdapat lima rasio keuangan yang dapat dijadikan alat pengukuran dalam melakukan analisis dan bahasan temuan dalam melakukan penilaian pada perspektif keuangan yaitu:

\section{Current Ratio}

Tabel 1.1

Current Ratio PT. YYY periode 2013 - 2017

\begin{tabular}{|c|c|c|c|}
\hline Tahun & Aktiva lancar & Liabilitas lancar & Current ratio \\
\hline 2013 & $247,857,397,601$ & $116,047,687,479$ & $213.58 \%$ \\
\hline 2014 & $291,703,923,959$ & $126,276,853,645$ & $231 \%$ \\
\hline
\end{tabular}

\footnotetext{
${ }^{1}$ Kaplan, Robert S., Norton, David P., "Balanced Scorecard, Translating strategy Into Action", Boston-Massachussets: Harvard Bussiness School Press, 1996.

${ }^{2}$ Kaplan, Robert S., Norton, David P., "Balanced Scorecard, Translating strategy Into Action”, Boston-Massachussets: Harvard Bussiness School Press, 1996
} 


\begin{tabular}{|c|c|c|c|}
\hline \hline 2015 & $277,613,187,155$ & $286,615,738,284$ & $96.86 \%$ \\
\hline 2016 & $428,567,605,198$ & $306,380,464,035$ & $139.88 \%$ \\
\hline 2017 & $549,832,698,772$ & $218,324,457,532$ & $251.84 \%$ \\
\hline \multicolumn{3}{|c|}{ Rata-rata } & $186.63 \%$ \\
\hline
\end{tabular}

Sumber: data sekunder yang diolah dari laporan keuangan PT. YYY

2. Debt Ratio

Tabel 1.2

Debt Ratio PT. YYY periode $2013-2017$

\begin{tabular}{|c|c|c|c|}
\hline Tahun & Total Kewajiban & Total Aset & Debt Ratio \\
\hline 2013 & $155,656,428,104$ & $289,248,296,601$ & $53.81 \%$ \\
\hline 2014 & $175,026,266,925$ & $333,300,923,959$ & $52.51 \%$ \\
\hline 2015 & $340,265,808,944$ & $341,924,549,155$ & $99.51 \%$ \\
\hline 2016 & $374,806,285,205$ & $471,000,548,398$ & $79.58 \%$ \\
\hline 2017 & $295,240,328,032$ & $592,846,588,772$ & $49.80 \%$ \\
\hline \multicolumn{4}{|c|}{ Rata-rata } \\
\hline
\end{tabular}

Sumber: data sekunder yang diolah dari laporan keuangan PT. YYY

3. Return on equity $(R O E)$

Tabel 1.3

Return on Equity PT. YYY periode 2013 - 2017

\begin{tabular}{|c|c|c|c|}
\hline Tahun & Laba bersih & Total ekuitas & Return on equity \\
\hline 2013 & $32,428,021,439$ & $362,035,920,275$ & $8.96 \%$ \\
\hline 2014 & $48,797,606,975$ & $383,244,828,249$ & $12.73 \%$ \\
\hline 2015 & $2,130,837,908$ & $425,443,822,343$ & $0.5 \%$ \\
\hline 2016 & $28,005,743,764$ & $445,632,584,385$ & $6.28 \%$ \\
\hline 2017 & $50,003,774,108$ & $525,444,828,985$ & $9.52 \%$ \\
\hline \multicolumn{4}{|c|}{ Rata-rata } \\
\hline
\end{tabular}

Sumber: data sekunder yang diolah dari laporan keuangan PT. YYY

4. Return on Investment (ROI)

Tabel 1.4

Return on Investment PT. YYY periode 2013 - 2017

\begin{tabular}{|c|c|c|c|}
\hline Tahun & Laba bersih & Total aset & Return on investment \\
\hline 2013 & $32,428,021,439$ & $289,248,296,601$ & $11.21 \%$ \\
\hline 2014 & $48,797,606,975$ & $333,300,923,959$ & $14.64 \%$ \\
\hline 2015 & $2,130,837,908$ & $341,924,549,155$ & $0.62 \%$ \\
\hline 2016 & $28,005,743,764$ & $471,000,548,398$ & $5.95 \%$ \\
\hline 2017 & $50,003,774,108$ & $592,846,588,772$ & $8.43 \%$ \\
\hline \multicolumn{4}{|c|}{ Rata-rata } \\
\hline
\end{tabular}

Sumber: data sekunder yang diolah dari laporan keuangan PT. YYY

5. Total Assets Turn Over (TATO)

Tabel 1.5

Total Assets Turn Over PT. YYY periode $2013-2017$

Tahun

Penjualan

Total Aset

Total Assets Turn 


\begin{tabular}{|c|c|c|c|}
\hline & & & Over \\
\hline 2013 & $620,645,659,530$ & $289,248,296,601$ & $214.57 \%$ \\
\hline 2014 & $706,874,535,578$ & $333,300,923,959$ & $212.08 \%$ \\
\hline 2015 & $489,684,248,385$ & $341,924,549,155$ & $143.21 \%$ \\
\hline 2016 & $590,485,792,953$ & $471,000,548,398$ & $125.37 \%$ \\
\hline 2017 & $762,592,572,943$ & $592,846,588,772$ & $128.63 \%$ \\
\hline \multicolumn{3}{|c|}{ Rata-rata } & $164.77 \%$ \\
\hline
\end{tabular}

Sumber: data sekunder yang diolah dari laporan keuangan PT. YYY

\section{Penilaian Kinerja pada Perspektif Proses Bisnis Internal}

Penilaian proses bisnis internal pada PT. YYY dilakukan pengukuran terhadap tingkat mutu yang dihasilkan.

Tabel 1.6

Tingkat kecacatan pada produk hasil produksi PT. YYY periode tahun $2013-2017$

\begin{tabular}{|c|c|c|c|c|c|}
\hline Keterangan & 2013 & 2014 & 2015 & 2016 & 2017 \\
\hline $\begin{array}{c}\text { Total } \\
\text { Produksi } \\
\text { (liter) }\end{array}$ & $126,983,755$ & $140,722,616$ & $130,639,419$ & $107,162,964$ & $149,535,257$ \\
\hline $\begin{array}{c}\text { Total Produk } \\
\text { Cacat (liter) }\end{array}$ & $5,738,944$ & $7,480,386$ & $6,036,219$ & $4,358,148$ & $5,649,857$ \\
\hline $\begin{array}{c}\text { Presentase } \\
\text { produk cacat }\end{array}$ & $4.52 \%$ & $5.31 \%$ & $4.62 \%$ & $4.07 \%$ & $3.78 \%$ \\
\hline
\end{tabular}

Sumber data : PT. YYY

\section{Penilaian Kinerja pada Perspektif Pertumbuhan dan Pembelajaran}

Pengukuran ini bertujuan agar perusahaan dapat mengetahui tingkat produktivitas seluruh karyawan di dalam perusahaan..

1. Tingkat Pelatihan pada Karyawan

Tabel 1.7

Tingkat Pelatihan Karyawan pada PT. YYY periode tahun 2013 - 2017

\begin{tabular}{|c|c|c|c|}
\hline Tahun & Jumlah Karyawan & $\begin{array}{c}\text { Jumlah karyawan } \\
\text { yang mengikuti } \\
\text { pelatihan }\end{array}$ & $\begin{array}{c}\text { Tingkat Pelatihan } \\
\text { Karyawan }\end{array}$ \\
\hline 2013 & 290 & 216 & $74.48 \%$ \\
\hline 2014 & 322 & 227 & $70.5 \%$ \\
\hline 2015 & 338 & 229 & $67.75 \%$ \\
\hline 2016 & 312 & 222 & $71.15 \%$ \\
\hline 2017 & 329 & 239 & $72.64 \%$ \\
\hline \multicolumn{4}{|c}{ Rata-rata } \\
\hline
\end{tabular}

Sumber data : PT. YYY

2. Tingkat Kepuasan Kerja pada Karyawan

Tabel 1.8

Tingkat Kepuasan Kerja Karyawan PT. YYY periode tahun 2013 - 2017

\begin{tabular}{|l|c|c|c} 
Tahun & Jumlah Karyawan & $\begin{array}{c}\text { Jumlah Karyawan } \\
\text { yang puas dan sangat } \\
\text { puas }\end{array}$ & $\begin{array}{c}\text { Tingkat Kepuasan } \\
\text { Karyawan dalam } \\
\text { bekerja }\end{array}$ \\
\hline
\end{tabular}




\begin{tabular}{|c|c|c|c|}
\hline \hline 2013 & 290 & 249 & $85.86 \%$ \\
\hline 2014 & 322 & 283 & $87.89 \%$ \\
\hline 2015 & 328 & 255 & $77.74 \%$ \\
\hline 2016 & 312 & 269 & $86.22 \%$ \\
\hline 2017 & 329 & 296 & $89.97 \%$ \\
\hline \multicolumn{3}{|c|}{ Rata-rata } & $85.54 \%$ \\
\hline
\end{tabular}

Sumber data : PT. YYY

3. Tingkat ketepatan waktu karyawan dalam menyelesaikan pekerjaan

Tabel 1.9

Tingkat ketepatan waktu menyelesaikan pekerjaan PT. YYY periode tahun 2013 - 2017

\begin{tabular}{|c|c|c|c|}
\hline Tahun & $\begin{array}{c}\text { Jumlah pekerjaan } \\
\text { yang harus } \\
\text { dituntaskan }\end{array}$ & $\begin{array}{c}\text { Jumlah pekerjaan } \\
\text { yang selesai tepat } \\
\text { pada waktunya }\end{array}$ & $\begin{array}{c}\text { Tingkat ketepatan } \\
\text { waktu karyawan } \\
\text { dalam menyelesaikan } \\
\text { pekerjaan }\end{array}$ \\
\hline 2013 & 580 & 561 & $96.72 \%$ \\
\hline 2014 & 677 & 662 & $97.78 \%$ \\
\hline 2015 & 597 & 558 & $93.47 \%$ \\
\hline 2016 & 634 & 623 & $98.26 \%$ \\
\hline 2017 & 691 & 680 & $98.41 \%$ \\
\hline \multicolumn{4}{|r}{} \\
\hline
\end{tabular}

Sumber : Data sekunder PT. YYY

\section{Penilaian Kinerja pada Perspektif Pelanggan}

Penilaian pada perspektif ini diukur dari apa saja yang telah dilakukan oleh PT. YYY dalam memuaskan para pelanggan dan menjaga hubungan baik dengan para pelanggan.

1. Tingkat Retensi Pelanggan

Tabel 2.1

Tingkat Retensi Pelanggan PT. YYY periode tahun 2013 - 2017

\begin{tabular}{|c|c|c|c|}
\hline Tahun & $\begin{array}{c}\text { Jumlah pelanggan } \\
\text { yang melakukan } \\
\text { repeat order }\end{array}$ & $\begin{array}{c}\text { Jumlah pelanggan } \\
\text { dalam satu tahun }\end{array}$ & $\begin{array}{c}\text { Tingkat Retensi } \\
\text { Pelanggan }\end{array}$ \\
\hline 2013 & 79 & 92 & $85.87 \%$ \\
\hline 2014 & 88 & 97 & $90.72 \%$ \\
\hline 2015 & 67 & 95 & $70.53 \%$ \\
\hline 2016 & 89 & 107 & $83.18 \%$ \\
\hline 2017 & 105 & 119 & $88.23 \%$ \\
\hline \multicolumn{4}{|c|}{ Rata-rata } \\
\hline
\end{tabular}

Sumber Data : PT. YYY

2. Tingkat Akuisisi Pelanggan

Tabel 2.2

Tingkat Akuisisi Pelanggan pada PT. YYY periode tahun 2013 - 2017

\begin{tabular}{|c|c|c|c|}
\hline Tahun & $\begin{array}{c}\text { Jumlah pelanggan } \\
\text { baru }\end{array}$ & $\begin{array}{c}\text { Jumlah keseluruhan } \\
\text { pelanggan }\end{array}$ & $\begin{array}{c}\text { Tingkat Akuisisi } \\
\text { Pelanggan }\end{array}$ \\
\hline 2013 & 4 & 92 & $4.35 \%$ \\
\hline 2014 & 5 & 97 & $5.15 \%$ \\
\hline
\end{tabular}




\begin{tabular}{|c|c|c|c|}
\hline \hline 2015 & 3 & 95 & $3.16 \%$ \\
\hline 2016 & 12 & 107 & $11.21 \%$ \\
\hline 2017 & 12 & 119 & $10.08 \%$ \\
\hline \multicolumn{3}{|c|}{ Rata-rata } \\
\hline
\end{tabular}

Sumber Data : PT. YYY

3. Tingkat Komplain dari Pelanggan

Tabel 2.3

Tingkat Komplain dari Pelanggan PT. YYY periode tahun 2013 - 2017

\begin{tabular}{|c|c|c|c|}
\hline Tahun & Jumlah Komplain & $\begin{array}{c}\text { Jumlah Pelanggan } \\
\text { dalam satu tahun }\end{array}$ & $\begin{array}{c}\text { Tingkat Komplain } \\
\text { dari Pelanggan }\end{array}$ \\
\hline 2013 & 11 & 92 & $11.96 \%$ \\
\hline 2014 & 14 & 97 & $14.43 \%$ \\
\hline 2015 & 8 & 95 & $8.42 \%$ \\
\hline 2016 & 12 & 107 & $11.21 \%$ \\
\hline 2017 & 9 & 119 & $7.56 \%$ \\
\hline \multicolumn{4}{|c|}{ Rata-rata } \\
\hline
\end{tabular}

Sumber Data : PT. YYY

\section{KESIMPULAN}

Penilaian perspektif keuangan pada PT. YYY menunjukkan adanya perbaikan pada tingkat current ratio, debt ratio, dan ROE pada perusahaan secara keseluruhan dari tahun 2013 sampai dengan 2017. Tingkat perbaikan tersebut dapat kita lihat dari tingkat current ratio dan tingkat Return on Equity yang meningkat dan tingkat debt ratio yang menurun dari tahun 2013 ke tahun 2017. Namun demikian, tingkat ROI dan TATO mengalami penurunan dalam periode tersebut.

Pada perspektif bisnis internal, PT. YYY sudah cukup baik dalam meminimalisir tingkat kecacatan pada produk yang dihasilkan. Secara keseluruhan, tingkat kecacatan produk pada tahun 2017 lebih rendah dibandingkan pada tahun 2013 yang berarti perusahaan sudah cukup baik dalam melakukan perbaikan pada kinerja proses bisnis internal.

Penilaian pada proses pertumbuhan dan pembelajaran terhadap PT. YYY dapat dilihat dari meningkatnya tingkat kepuasan karyawan dalam bekerja dan tingginya tingkat ketepatan waktu karyawan dalam menyelesaikan pekerjaannya selama periode tahun 2013 sampai dengan 2017. Namun demikian, tingkat presentase jumlah karyawan yang mengikuti pelatihan mengalami penurunan dari tahun 2013 sampai dengan 2017

Penilaian pada perspektif pelanggan menunjukkan bahwa perusahaan sudah cukup baik dalam memuaskan pelanggan. Hal ini dapat kita lihat dari tingkat retensi dan akuisisi pelanggan pada tahun 2017 yang lebih tinggi dibandingkan pada tahun 2013. Sedangkan tingkat komplain pada tahun 2017 yang lebih rendah dibandingkan pada tahun 2013 menunjukkan bahwa perusahaan sudah cukup baik dalam melakukan perbaikan di dalam memperbaiki mutu produk dan pelayanan pada pelanggan selama periode lima tahun tersebut.

\section{Daftar Pustaka}

B. Waspodo. Kerangka Kerja Pengukuran Kinerja Berdasarkan Balanced Scorecard untuk Departemen Sistem Informasi. Komunikasi Massa Volume 5 Nomor 1, 2009 
Bathala C. T., K.P. Moon dan R. P. Rao. 1994. Managerial ownership, debt policy, and the impact of institutional holdings: An agency perspective, Financial Management

David, F.R. Strategic Management: Concepts and Cases, Harlow, UK: Pearson. 2013

Glueck, William F., \& Jauch, Lawrence, R. 1989. Manajemen Strategi dan Kebijakan Perusahaan (edisi 2). Jakarta : Erlangga.

Helfert, Erich. A, 2002. "Techniques of Financial Analysis”, Mc. Graw Hill/Irwin.

Kristianti, Rina Adi. 2017. Manajemen Strategik. Pustaka Mandiri

Laporan Laba Rugi dan Laporan Keuangan PT. YYY.

Luis, Suwardi \& Prima A. Biromo 2008, Step by Step in Cascading Balanced Scorecard to Functional Scorecards, Jakarta: PT. Gramedia.

Mulyadi. 2001. Balanced Scorecard: Alat Manajemen Kontemporer untuk Pelipatganda Kinerja Keuangan Perusahaan. (edisi ke-2). Jakarta: Salemba Empat.

Riyanto, Bambang. (2001). Dasar-Dasar Pembelanjaan Perusahaan. Yogyakarta: BPFE.

Robert S. Kaplan, D. P. N. (2001). The Strategy focused Organization: How Balanced Scorecard Companies Thrive in the New Business Environment. Boston: Harvard Business School Press.

Sawir, A. 2009. Analisa Kinerja Keuangan dan Perencanaan keuangan Perusahaan, PT. Gramedia Pustaka Utama, Jakarta.

Sekaran, Uma \& Bougie Roger. (2010). Research methods for business, a skill building approach. USA : John Wiley \& Sons.

Tunggal, Amin Widjaja. (2001). Pengukuran Kinerja Dengan Balanced Scorecard. Harvindo, Jakarta.

Tunggal, Amin Widjaja. (2002). Memahami Konsep Balanced Scorecard PT. Harvindo, Jakarta.

Wibowo. 2007. Manajemen Kinerja :Rajawali Pers. Jakarta.

Yuwono, Sony dan Edy Sukamo dan Muhammad Ichsan. (2003). Petunjuk Praktis Penyusunan Balanced Scorecard: Menuju Organisasi Yang Berfokus Pada Strategi. PT. Gramedia Pustaka Utama, Jakarta. 
